Check for updates

Cite this: RSC Adv., 2017, 7, 25885

\title{
Nanoscale Pd supported on 3D porous carbon for enhanced selective oxidation of benzyl alcohol $\uparrow$
}

\author{
Shuo Niu, ${ }^{a}$ Wenyao Guo, ${ }^{a}$ Tsung-Wu Lin, ${ }^{b}$ Weizhen $\mathrm{Yu}^{a}{ }^{a}$ Yifei $\mathrm{Wu}{ }^{a}$ Xiaobo Ji ${ }^{c}{ }^{\mathrm{c}}$ \\ and Lidong Shao iD *a \\ In this work, a 3D porous carbon framework (PCF) supporting palladium nanoparticles (Pd/PCF) was \\ synthesized by a simple and economical method and used for catalyzing benzyl alcohol oxidation in \\ a continuous-flow reactor. Structural and surface characterization revealed that this coral-like PCF with \\ increased hydrophobic and basic surface properties promotes the adsorption and desorption of the \\ reactant and products, and also suppresses the disproportionation and facilitates the oxidation of benzyl \\ alcohol at the same time. The Pd/PCF catalyst exhibited an improved performance in activity, selectivity, \\ and stability when compared to the same Pd supported on a typical activated carbon (AC).
}

Received 30th March 2017 Accepted 9th May 2017

DOI: 10.1039/c7ra03665e

rsc.li/rsc-advances supports such as active carbon (AC) and carbon nanotubes (CNTs). ${ }^{7-9,17}$ However, to the best of our knowledge, there have been no reports on the use of 3D PCFs as support materials for any metal to catalyze selective alcohol oxidations.

In this work, a 3D PCF was prepared from only acetone and sodium hydroxide by an extremely simplified and scalable approach, and used as the support for Pd nanoparticles in benzyl alcohol oxidation. Pd supported on AC (Pd/AC) was prepared and applied under the same conditions for comparison. A continuous-flow system was used to evaluate the catalytic performance and to achieve rapid optimization of reaction conditions. The flow system also aids the collection of catalyst particles without filtration, thus directly revealing the information on catalytic stability. ${ }^{18}$ Herein, surface analyses of both fresh and reacted catalysts were carried out to better clarify the influence of catalyst supports.

\section{Results and discussion}

A PCF was prepared by an extremely simplified $\mathrm{NaOH}$-assisted treatment of acetone, as shown in Fig. 1. Briefly, $8 \mathrm{~g} \mathrm{NaOH}$ was mixed with $40 \mathrm{~mL}$ acetone and stirred by a magnetic stirrer for $1 \mathrm{~h}$. The liquid mixture was left in air for $120 \mathrm{~h}$, which gradually afforded a dark brown solid. Subsequent calcining at $600{ }^{\circ} \mathrm{C}$ and then at $1000{ }^{\circ} \mathrm{C}$ under He atmosphere yielded 3D PCFs. Pd nanoparticles supported on PCF (Pd/PCF) were prepared via an impregnation method, with a total metal loading of $1.16 \mathrm{wt} \%$ (measured by inductively coupled plasma optical emission spectrometer (ICP-OES)).

The morphology and microstructure of the as-prepared Pd/ PCF were characterized by scanning electron microscopy (SEM) and transmission electron microscopy (TEM). Fig. 2a and b show coral-like morphology of the PCF, composed of interconnected and distorted nanosheets with many micro-and 


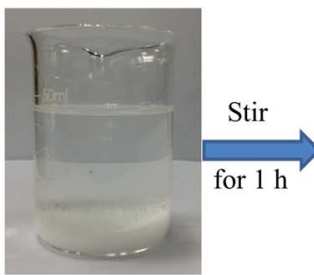

Acetone $+\mathrm{NaOH}$
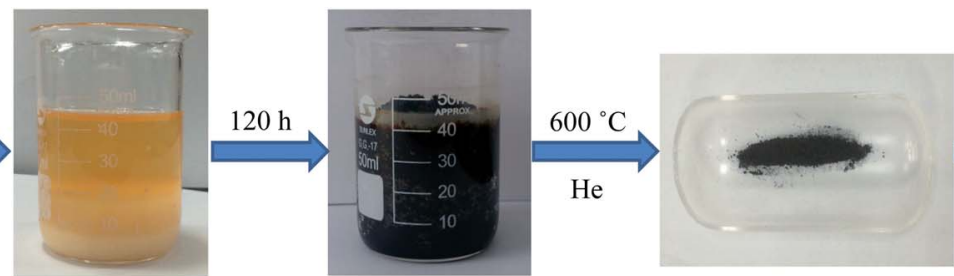

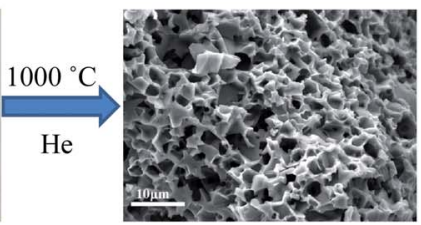

PCF

Fig. 1 Illustration of the preparation procedure for PCF.
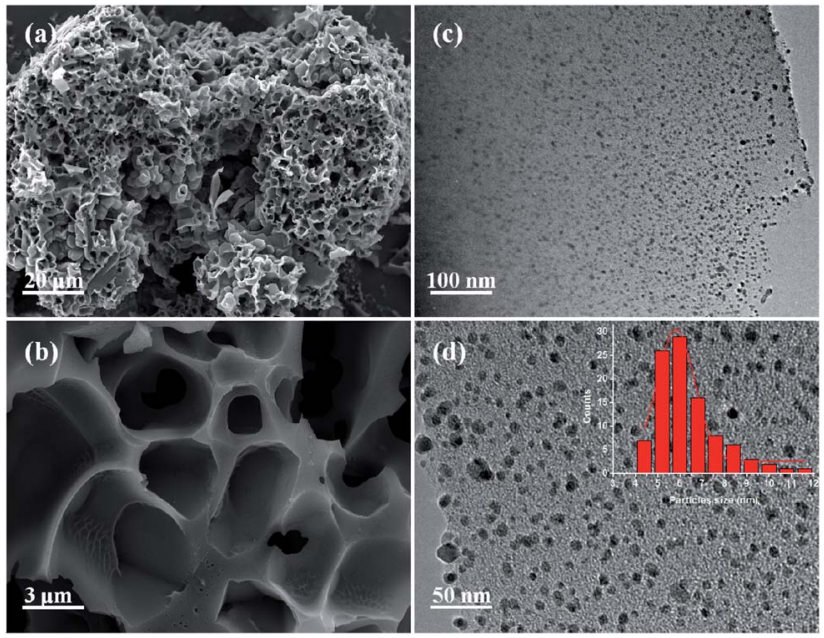

Fig. 2 ( $a$ and b) SEM images of the fresh PCF and ( $c$ and d) TEM images of the fresh Pd/PCF.

nano-sized pores. TEM images of Pd nanoparticles dispersed on the PCF support are shown in Fig. $2 \mathrm{c}$ and d, which exhibit welldistributed and 4-12 nm-long Pd nanoparticles supported on the PCF.

The liquid phase oxidation of benzyl alcohol was carried out in a continuous-flow three-phase reactor (Thales-Nano Phoenix Flow Reactor $\left.{ }^{\mathrm{TM}}\right)$. For catalytic comparisons, the $\mathrm{Pd} / \mathrm{AC}$ catalyst with a metal loading of $1.85 \mathrm{wt} \%$ (measured by ICP-OES) was prepared by impregnation and applied under the same conditions. The conversion of benzyl alcohol and the selectivity of benzaldehyde are shown in Fig. 3. The PCF-supported catalyst showed a significantly higher selectivity of $90.71 \%$ at $65.07 \%$ conversion, compared to that obtained with Pd/AC (76.91\% selectivity at $7.18 \%$ conversion). Additionally, after $1 \mathrm{~h}$ of reaction, the selectivity of $\mathrm{Pd} / \mathrm{AC}$ decreased by $\sim 10 \%$, while no obvious decrease in the activity and selectivity was observed in the case of Pd/PCF. When looking at the optimum oxygen flow rate, the conversion of benzyl alcohol increased with the rise of oxygen flow rate from $3 \mathrm{~mL} \min ^{-1}$ to $5 \mathrm{~mL} \mathrm{~min}^{-1}$, whereas further increase of oxygen flow rate resulted in a gradual decrease of benzyl alcohol conversion (Fig. S1†). This observation may be due to the reduced retention time of benzyl alcohol in the catalyst column in contact with oxygen. The effect of temperature was also carried out, the conversion of benzyl alcohol increased with the increase of temperature, while the
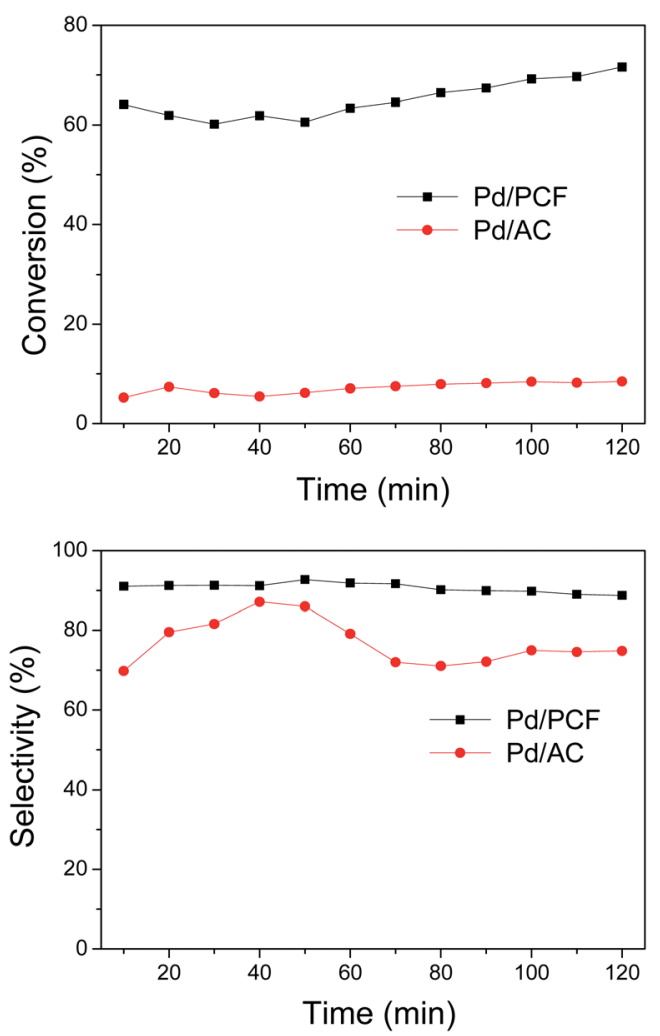

Fig. 3 Catalytic performances of $\mathrm{Pd} / \mathrm{PCF}$ and $\mathrm{Pd} / \mathrm{AC}$ catalysts for benzyl alcohol oxidation.

selectively of benzaldehyde was reduced accordingly (Fig. S2 $\dagger$ ). It is known that solvent-free oxidation of benzyl alcohol can be accomplished over Pd catalysts. ${ }^{19-21}$ The Pd/PCF was applied to the solvent-free catalytic reaction, in which the conversion and selectivity were $10.22 \%$ and $78.02 \%$, respectively. Since the properties of AC might influence of catalytic performance to a great extent, the same metal loading of Pd supported on the carbon nanotube (Pd/CNT) catalyst was also carried out under the same conditions. The Pd/CNT catalyst showed a selectivity of $37.24 \%$ at $24.95 \%$ conversion, which is also much lower than that of $\mathrm{Pd} / \mathrm{PCF}$.

In terms of the catalytic performance (TOF) of Pd catalysts in benzyl alcohol oxidation reaction, solvent-free conditions were applied to calculate the TOF. The performances of Pd supported on PCF, AC and CNT were carried out at the same conditions. The TOF of Pd/PCF $\left(2826.6 \mathrm{~h}^{-1}\right)$ is higher than Pd/AC $(571.2$ 
$\left.\mathrm{h}^{-1}\right)$ and $\mathrm{Pd} / \mathrm{CNT}\left(1071.8 \mathrm{~h}^{-1}\right)$, which is in accordance to the reactivity of those three catalysts. The results of TOF indicate that the PCF support was not simply increased the dispersion of $\mathrm{Pd}$, but also increased the activity per site and thus increased the reactivity of $\mathrm{Pd} / \mathrm{PCF}$.

TEM overview images of both the fresh and used of Pd/PCF and $\mathrm{Pd} / \mathrm{AC}$ catalysts are shown in Fig. 4. The Pd particles on the PCF exhibit a more homogeneous distribution than those on AC. For the used catalyst in both cases, no obvious structural difference was observed. The Pd/PCF showed no apparent growth in the size of the Pd particles after oxidation and maintained a good distribution of particles. However, in the case of $\mathrm{Pd} / \mathrm{AC}$, a considerable number of $\mathrm{Pd}$ particles were observed to have undergone coalescence to form bigger and irregularly shaped particles, probably due to the accumulated carbonaceous deposition and metal leaching.

$\mathrm{X}$-ray diffraction (XRD) was applied to the fresh and used catalysts to investigate the crystal structure. As shown in Fig. 5, the remarkable peak at $\sim 23.7^{\circ}$ was consistent with the (002) diffraction of carbonaceous materials, indicating that the support has some resemblance to the graphite structure. ${ }^{22}$ In addition, four other obvious diffraction peaks of $\mathrm{Pd} / \mathrm{PCF}$ and $\mathrm{Pd} / \mathrm{AC}$ were observed at $2 \theta=39.9^{\circ}, 46.4^{\circ}, 67.9^{\circ}$, and $81.8^{\circ}$, corresponding to the face-centered cubic (fcc) structure with (111), (200), (220), and (311) planes of the Pd nanoparticles. ${ }^{23}$ The sharp and distinct diffraction peaks indicated that the Pd nanoparticles form complete crystal structures and show a high degree of crystallinity.

The average size of the Pd nanoparticles (d) was estimated using the Scherrer's equation (eqn (1)) for the (111) peak at $2 \theta=$ $40^{\circ}$ after background subtraction:

$$
d=k \lambda /(\beta \cos \theta)
$$

where $k$ is a coefficient, generally taken as $0.9, \lambda$ is the wavelength of the X-ray radiation (1.5418 $\AA$ ), $\beta$ is the full width at half maximum (FWHM) measured in radians, and $\theta$ is the angle
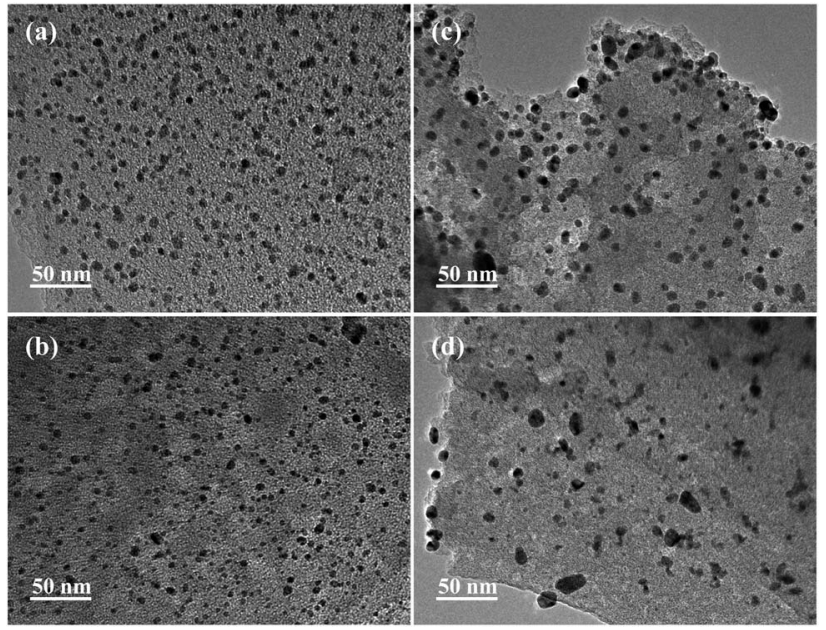

Fig. 4 TEM images of Pd/PCF catalyst (a) before reaction and (b) after reaction, and those of $\mathrm{Pd} / \mathrm{AC}$ catalyst (c) before reaction and (d) after reaction
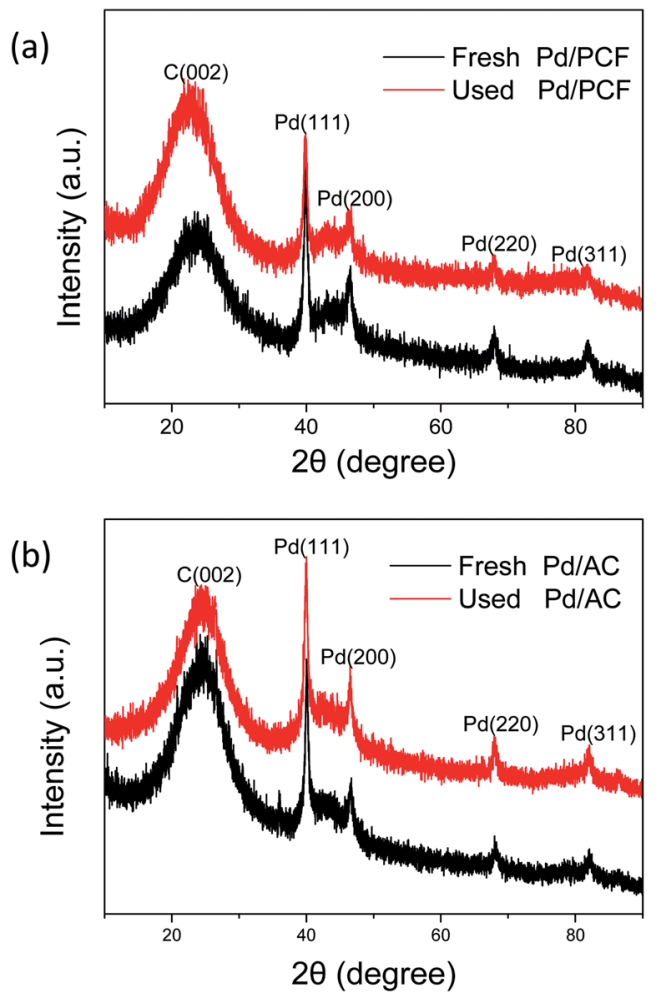

Fig. 5 XRD patterns of (a) Pd/PCF and (b) Pd/AC catalysts before and after reaction.

measured for the position of Pd diffraction peaks. The average Pd nanoparticle diameter calculated from the FWHM of the Pd (311) peak for the fresh Pd/PCF catalyst was $12.6 \mathrm{~nm}$, which is nearly equal to that of the used catalyst $(12.3 \mathrm{~nm})$. Thus, there was no obvious difference between the fresh and used Pd/PCF. However, in the case of Pd/AC, the average diameter of the Pd particles slightly increased from $12.0 \mathrm{~nm}$ to $13.6 \mathrm{~nm}$, which is in good agreement with the TEM results.

Fig. 6 shows the Raman spectra of the fresh and used catalysts. The qualitative analysis of the carbon nanostructures, based on the intensity ratio of the $\mathrm{D}$ band to the $\mathrm{G}$ band $\left(I_{\mathrm{D}} / I_{\mathrm{G}}\right)$, revealed the in-plane crystallite dimensions and the in-plane crystallite dimensions and the in-plane and edge defects in the above materials. The $I_{\mathrm{D}} / I_{\mathrm{G}}$ ratios of the fresh AC, fresh $\mathrm{Pd} /$ $\mathrm{AC}$, and used $\mathrm{Pd} / \mathrm{AC}$ were 1.07, 1.09, and 1.08, respectively. Similar peak positions and $I_{\mathrm{D}} / I_{\mathrm{G}}$ values were observed for $\mathrm{AC}$, implying that these samples possess similar degrees of graphitization.

The $I_{\mathrm{D}} / I_{\mathrm{G}}$ ratios of the fresh PCF and fresh Pd/PCF were 1.05 and 1.06, respectively, while that of Pd/PCF after the oxidation reaction was 1.13. Nevertheless, no obvious structural difference was observed between the fresh and used catalysts.

The composition of the catalysts was determined by XPS. As shown in Fig. 7, both Pd/PCF and Pd/AC exhibited the evidence peak of $\mathrm{C} \mathrm{1s}$, and six different peaks, representing different oxygen-containing groups, could be obtained owing to deconvolution. The main peak at $284.5 \mathrm{eV}$ could be attributed to the $\mathrm{sp}^{2}$-hybridized carbon atoms, $\mathrm{sp}^{3}$-hybridized carbon atoms were 

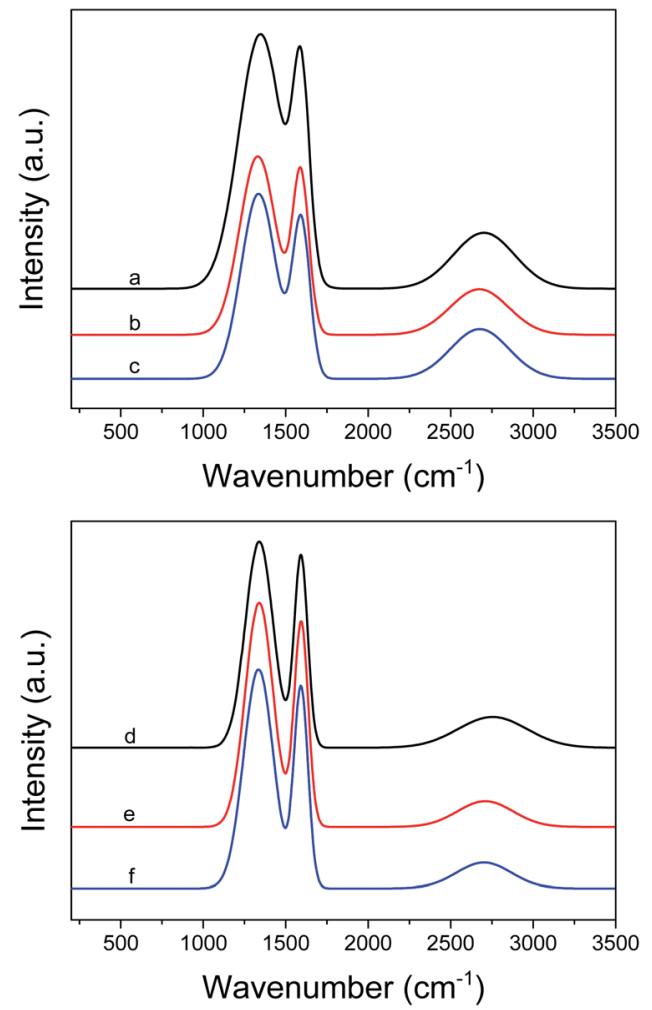

Fig. 6 Raman spectra of (a) fresh PCF, (b) Pd/PCF catalyst before reaction, (c) Pd/PCF catalyst after reaction, (d) fresh $A C$, (e) $P d / A C$ catalyst before reaction, and (f) $\mathrm{Pd} / \mathrm{AC}$ catalyst after reaction.
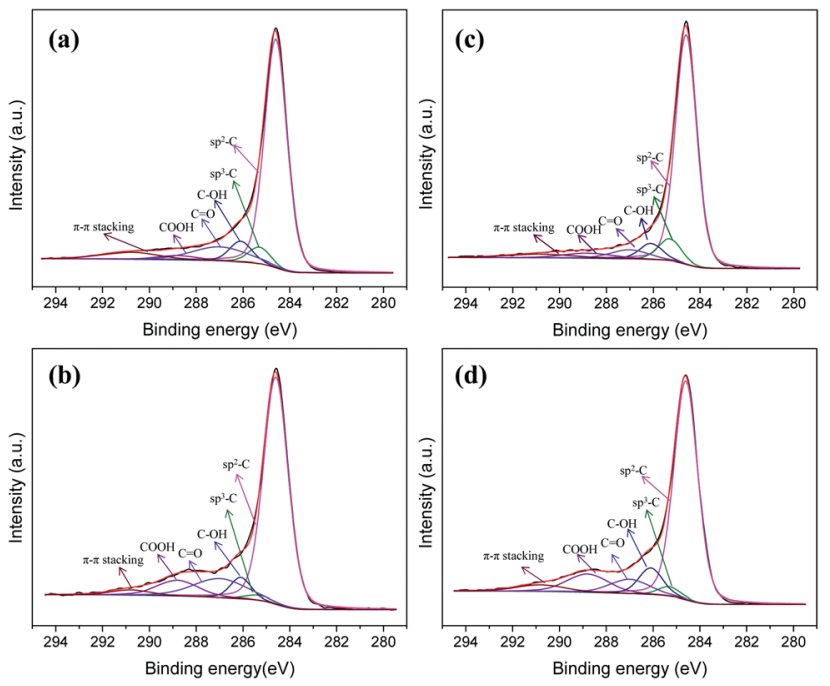

Fig. 7 Deconvoluted C 1s XPS patterns of the (a) Pd/PCF catalyst before reaction, (b) Pd/PCF catalyst after reaction, (c) Pd/AC catalyst before reaction, and (d) $\mathrm{Pd} / \mathrm{AC}$ catalyst after reaction.

represented by the peak at $285.2 \mathrm{eV}$. In addition, the three peaks at $286.3 \mathrm{eV}, 287.4 \mathrm{eV}$, and $288.8 \mathrm{eV}$ were ascribed to $-\mathrm{C}-\mathrm{O}-$ (like alcohol and ether), $-\mathrm{C}=\mathrm{O}$ (like ketone and aldehyde), and -COO- (like carboxylic and carbonyl) groups, respectively. ${ }^{24}$ The atomic ratios (C 1s/O 1s) of the different catalyst samples detected by XPS are shown in Table 1 . The oxygen content on
Table 1 Summary of the core-level XPS spectra of the catalysts, both fresh and after reaction

\begin{tabular}{lllll}
\hline Catalyst type & C 1s (\%) & O 1s (\%) & $\begin{array}{l}\text { Pd 3d } \\
(\%)\end{array}$ & $\begin{array}{l}\text { C 1s/O } \\
1 \mathrm{~s}\end{array}$ \\
\hline Fresh Pd/PCF & 89.32 & 10.17 & 0.51 & 8.78 \\
Reacted Pd/PCF & 85.44 & 13.28 & 1.28 & 6.43 \\
Fresh Pd/AC & 80.84 & 18.40 & 0.76 & 4.39 \\
Reacted Pd/AC & 83.63 & 15.75 & 0.62 & 5.31 \\
\hline
\end{tabular}

the surface of Pd/PCF was lower than that on the Pd/AC surface, indicating that the Pd/PCF possess less oxygenated functional groups. Comparing the catalyst before and after the reaction, an opposite trend was observed between the oxygen contents on $\mathrm{Pd} / \mathrm{PCF}$ and Pd/AC. For Pd/PCF, the oxygen content increased and the $\mathrm{C} 1 \mathrm{~s} / \mathrm{O} 1 \mathrm{~s}$ ratio decreased, suggesting an accumulation of oxygenated compounds during the reaction. However, the oxygen content on Pd/AC decreased after the reaction, probably owing to the loss of oxygenated functional groups due to the leaching of the metal particles.

We carried out XPS measurements to clarify the chemical state of the Pd nanoparticles anchored on the catalyst samples and to characterize the surface and near-surface properties of both fresh and used catalysts. Fig. 8 shows the XPS signals of the $\mathrm{Pd} / \mathrm{PCF}$ and $\mathrm{Pd} / \mathrm{AC}$ catalysts before and after reaction, between $333 \mathrm{eV}$ and $350 \mathrm{eV}$. The signals were fitted with multiple peaks. From the Pd 3d spectrum, we could find two types of double peaks, named Pd 3d (3/2) and Pd 3d (5/2) peak. The shift degrees of the two types of peaks were similar, and therefore, only the Pd 3d (5/2) peak has been discussed here.

The Pd 3d (5/2) peak ranges from $335.5 \mathrm{eV}$ to $335.8 \mathrm{eV}$ were found to represent the monometallic Pd nanoparticles. As shown in Fig. 8, the peaks at $335.5 \pm 0.2 \mathrm{eV}$ corresponded to $\operatorname{Pd}(0)$, and the other peak at $337.45 \mathrm{eV}$ indicated the formation of Pd-O bonds. ${ }^{25,26}$ The intensity of the peaks suggested that majority of the $\operatorname{Pd}$ nanoparticles are $\operatorname{Pd}(0)$, and that Pd also exists in the catalysts in the form of Pd(II), which can easily bond with the $\mathrm{O}$ atom. As shown in Fig. 8a and b, the Pd/PCF catalysts before and after reaction exhibited no obvious shift, indicating that the size of the Pd particles was almost unchanged. This further suggested that the Pd particles and the supports might be closely bonded together. ${ }^{27}$ However, the spectra of the fresh Pd/AC in Fig. $8 \mathrm{c}$ and that of the used Pd/AC in Fig. 8d showed a clear negative binding energy shift of $\sim 0.7 \mathrm{eV}$ in the $\operatorname{Pd}(0) 3 \mathrm{~d}$ (5/2) peaks for the used Pd/AC catalysts due to increase in the size of the Pd nanoparticles, which is in good agreement with the TEM and XRD results.

The TPD results allow the identification and quantification of the functional groups present on the carbonaceous material surface by peak assignment. TPD spectra for both Pd/PCF and $\mathrm{Pd} / \mathrm{AC}$ are shown in Fig. 9. The $\mathrm{Pd} / \mathrm{AC}$ samples show $\mathrm{CO}_{2}$ release over a broad range of temperature (400-1000 K) because of the decomposition of different functionalities such as carboxylic acids, anhydrides, and lactones. ${ }^{28}$ On the contrary, PCFs released a very low amount of $\mathrm{CO}_{2}$ over the temperature range $400-650 \mathrm{~K}$, as a result of hydrophobic surface properties. The 

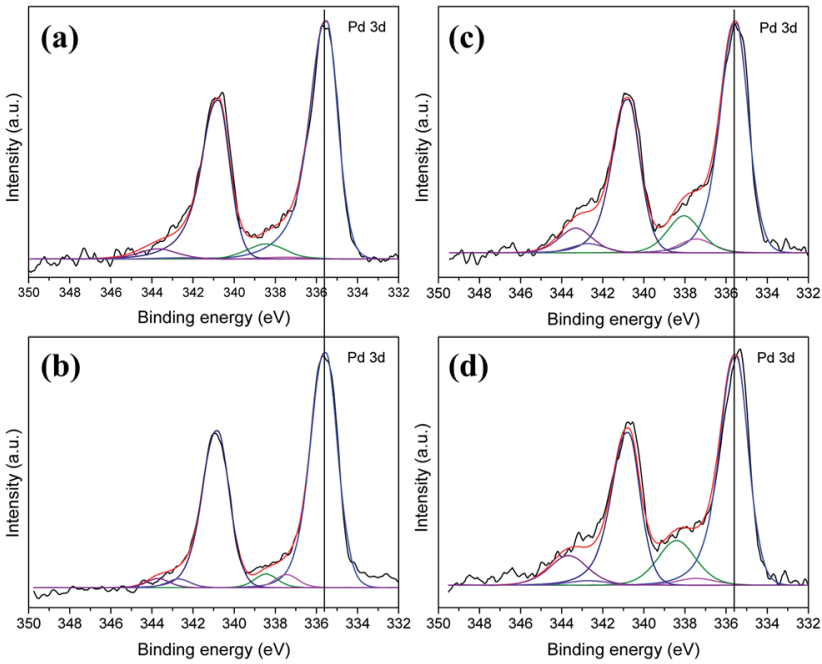

Fig. $8 \mathrm{Pd} \mathrm{3d} \mathrm{XPS} \mathrm{patterns} \mathrm{of} \mathrm{the} \mathrm{Pd/PCF} \mathrm{catalyst} \mathrm{(a)} \mathrm{before} \mathrm{reaction}$ and (b) after reaction, and those of $\mathrm{Pd} / \mathrm{AC}$ catalyst (c) before reaction and (d) after reaction.
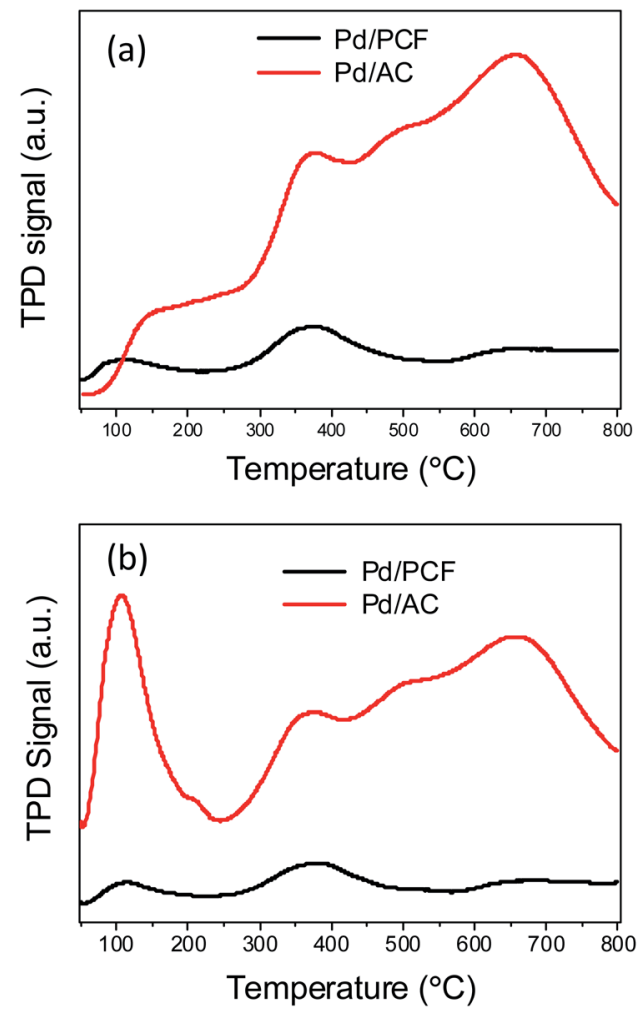

Fig. 9 (a) $\mathrm{CO}_{2}-\mathrm{TPD}$ and (b) $\mathrm{NH}_{3}-\mathrm{TPD}$ patterns of $\mathrm{Pd} / \mathrm{PCF}$ and $\mathrm{Pd} / \mathrm{AC}$ catalysts.

acidity of both $\mathrm{Pd} / \mathrm{PCF}$ and Pd/AC was also studied by the $\mathrm{NH}_{3}$ TPD profiles, and the results are displayed in Fig. 9b. The Pd/AC catalyst showed much higher desorption peaks than that of the $\mathrm{Pd} / \mathrm{PCF}$ catalyst at temperatures below $100{ }^{\circ} \mathrm{C}$ and over $350{ }^{\circ} \mathrm{C}$, which were ascribed to the physisorbed ammonia and the strongly acidic sites, respectively.
As reported by Villa et al., the hydrophilicity/hydrophobicity of the support surface can impact its activity in Pd-catalyzed alcohol oxidation. ${ }^{29}$ Herein, we could conclude that the benefit of using PCF as the support, with respect to both activity and selectivity, is mainly attributable to the hydrophobicity of the support surface. Both the TPD and XPS results indicate that the total number of O-containing functional groups in PCFs was much less than that in AC. This is in accordance with the observation that Pd/PCF showed a higher conversion than Pd/ $\mathrm{AC}$, implying that higher the hydrophobicity of the surface, higher is the catalyst activity. The hydrophobic surface of the PCF might provide the hydrophobic reactant (benzyl alcohol) with an easier access to the active sites, which also facilitates the product desorption at the same time, thus increasing the overall rate of the reaction. Contrarily, the surface of AC contained a high concentration of oxygen species, and their hydrophilic character had a negative effect on the affinity between the catalyst and the hydrophobic benzyl alcohol, especially when hydrophobic solvents like cyclohexane were used.

Moreover, the catalytic selectivity was also affected by the acidity/basicity of the support surface, which determined the preferential reaction route. As reported by Savara et al., there are two primary reaction pathways for the overall oxidation of benzyl alcohol to produce the desired benzaldehyde. ${ }^{30}$ One pathway is oxidation and the other is the disproportionation of benzyl alcohol. In the latter reaction pathway, an equimolar amount of toluene, the main byproduct, is produced along with benzaldehyde. According to the disproportionation mechanism, the formation of toluene involves cleavage of the $\mathrm{C}-\mathrm{O}$ bond of benzyl alcohol and is likely to be promoted in acidic conditions, whereas the $\mathrm{O}-\mathrm{H}$ cleavage leading to benzaldehyde formation prefers basic environments. Our observations confirmed that toluene formation by disproportionation was favored when $\mathrm{AC}$ with acidic properties was used as the support. In contrast, PCFs exhibiting basic characters promoted the oxidation of benzyl alcohol to form benzaldehyde, thus increasing the selectivity for the desired products.

Furthermore, it is noteworthy that the Pd nanoparticles supported on PCFs showed better stability than those on AC, as confirmed by comparing the XRD patterns, XPS spectra, and ICP data for both the fresh and used Pd/PCF and Pd/AC catalysts. All the results showed that a significant leaching of the Pd particles occurred on AC supports. Therefore, a high catalytic stability during the selective oxidation of benzyl alcohol was achieved using Pd supported on PCFs.

\section{Conclusions}

In this work, we used a simple and scalable method to synthesize a 3D porous carbon framework (PCF) with coral-like structure. This PCF was applied as a support for Pd nanoparticles and compared with activated carbon (AC) for the selective oxidation of benzyl alcohol in a continuous-flow reactor. The Pd/PCF catalyst exhibited enhanced activity with higher selectivity toward benzaldehyde and more resistance to deactivation than Pd/AC. We proposed that the hydrophobicity, basicity, and porosity of the support surface contribute to the 
improved catalytic performances in selective oxidation reactions. The excellent activity of Pd/PCF was attributed to the hydrophobicity of the support surface, which promotes the adsorption of the hydrophobic reactant (benzyl alcohol) and desorption of the products at the same time. The enhanced selectivity was ascribed to the basic character of the PCF surface, which suppresses the disproportionation and facilitates the oxidation of benzyl alcohol.

\section{Acknowledgements}

This work is supported by the National Natural Science Foundation of China (21403137).

\section{Notes and references}

1 M. N. Kopylovich, A. P. C. Ribeiro, E. C. B. A. Alegria, N. M. R. Martins, L. M. D. R. S. Martins and A. J. L. Pombeiro, Adv. Orgamomet. Chem., 2015, 63, 91-174.

2 A. Villa, N. Dimitratos, C. E. Chan-Thaw, C. Hammond, L. Prati and G. J. Hutchings, Acc. Chem. Res., 2015, 48, 1403-1412.

3 M. Sankar, N. Dimitratos, P. J. Miedziak, P. P. Wells, C. J. Kiely and G. J. Hutchings, Chem. Soc. Rev., 2012, 41, 8099-8139.

4 R. Long, H. Huang, Y. P. Li, L. Song and Y. J. Xiong, Adv. Mater., 2015, 27, 7025-7042.

5 A. N. Campbell and S. S. Stahl, Acc. Chem. Res., 2012, 45, 851863.

6 D. I. Enache, J. K. Edwards, P. Landon, B. Solsona-Espriu, A. F. Carley, A. A. Herzing, M. Watanabe, C. J. Kiely, D. W. Knight and G. J. Hutchings, Science, 2006, 311, 362365.

7 A. Villa, D. Wang, N. Dimitratos, D. S. Su, V. Trevisan and L. Prati, Catal. Today, 2010, 150, 8-15.

8 C. E. Chan-Thaw, A. Villa, P. Katekomol, D. S. Su, A. Thomas and L. Prati, Nano Lett., 2010, 10, 537-541.

9 C. M. A. Parlett, D. W. Bruce, N. S. Hondow, A. F. Lee and K. Wilson, ACS Catal., 2011, 1, 636-640.

10 J. K. Mobley and M. Crocker, RSC Adv., 2015, 5, 65780-65797. 11 P. Weerachawanasak, G. J. Hutchings, J. K. Edwards, S. A. Kondrat, P. J. Miedziak, P. Prasertham and J. Panpranot, Catal. Today, 2015, 250, 218-225.
12 Y. Wang, S. De and N. Yan, Chem. Commun., 2016, 52, 62106224.

13 A. Villa, M. Schiavoni and L. Prati, Catal. Sci. Technol., 2012, 2, 673-682.

14 B. S. Zhang, L. D. Shao, W. Zhang, X. Y. Sun, X. L. Pan and D. S. Su, ChemCatChem, 2014, 6, 2607-2612.

15 R. Arrigo, S. Wrabetz, M. E. Schuster, D. Wang, A. Villa, D. Rosenthal, F. Girsgdies, G. Weinberg, L. Prati, R. Schlogl and D. S. Su, Phys. Chem. Chem. Phys., 2012, 14, 10523-10532.

16 H. S. Hou, C. E. Banks, M. J. Jing, Y. Zhang and X. B. Ji, Adv. Mater., 2015, 27, 7861-7866.

17 A. Corma, H. Garcia and A. Leyva, J. Mol. Catal. A: Chem., 2005, 230, 97-105.

18 L. D. Shao, X. Huang, D. Teschner and W. Zhang, ACS Catal., 2014, 4, 2369-2373.

19 G. J. Wu, X. M. Wang, N. J. Guan and L. D. Li, Appl. Catal., B, 2013, 136-137, 177-185.

20 X. M. Wang, G. J. Wu, N. J. Guan and L. D. Li, Appl. Catal., B, 2012, 115, 7-15.

21 Y. T. Chen, Z. Guo, T. Chen and Y. H. Yang, J. Catal., 2010, 275, 11-24.

22 T. Q. Chen, Y. Liu, L. K. Pan, T. Lu, Y. F. Yao, Z. Sun, D. H. C. Chua and Q. Chen, J. Mater. Chem. A, 2014, 2, 4117-4121.

23 S. M. Shang, X. M. Yang and X. M. Tao, Polymer, 2009, 50, 2815-2818.

24 J. Luo, H. Yu, H. J. Wang, H. H. Wang and F. Peng, Chem. Eng. J., 2014, 240, 434-442.

25 A. Namdeo, S. M. Mahajani and A. K. Suresh, J. Mol. Catal. A: Chem., 2016, 421, 45-56.

26 Q. Wang, X. C. Cai, Y. Q. Liu, J. Y. Xie, Y. Zhou and J. Wang, Appl. Catal., B, 2016, 189, 242-251.

27 N. Tsubaki and K. Fujimoto, Top. Catal., 2003, 22, 325-335.

28 J. L. Figueiredo, M. F. R. Pereira, M. M. A. Freitas and J. J. M. Órfão, Carbon, 1999, 37, 1379-1389.

29 A. Villa, M. Plebani, M. Schiavoni, C. Milone, E. Piperopoulos, S. Galvagno and L. Prati, Catal. Today, 2012, 186, 76-82.

30 A. Savara, C. E. Chan-Thaw, I. Rossetti, A. Villa and L. Prati, ChemCatChem, 2014, 6, 3464-3473. 